\title{
Intelligence and development in Aarskog syndrome
}

\author{
Lindsay J Logie, Mary E M Porteous
}

\begin{abstract}
Aim-To test the hypothesis that overall intelligence quotient (IQ) is decreased in patients with Aarskog syndrome.

Methods-21 boys under 17 years of age with a confirmed clinical diagnosis of Aarskog syndrome were assessed using the Griffiths mental development scales and the British ability scales.

Results-IQ ranged from 68 to 128 and followed a normal distribution.

Conclusion-This study does not support the hypothesis that Aarskog syndrome is associated with a lowering of mean IQ.

(Arch Dis Child 1998;79:359-360)
\end{abstract}

Keywords: Aarskog syndrome; intelligence; genetics

Aarskog syndrome (facio-digital-genital syndrome) is a rare $\mathrm{X}$ linked condition characterised by short stature, facial anomalies, joint laxity particularly in the hands and feet, and shawl scrotum. The initial reports on the syndrome, ${ }^{12}$ describing 10 boys in two families, suggest a favourable prognosis for mental development although Scott's first case did have some early motor delay. Concerns regarding intellectual outcome were raised by Furukawa et al in $1972^{3}$ when one of four affected boys in one family had reading difficulties. Subsequently, comment was made about intelligence in a further 30 papers on Aarskog syndrome. Generally, affected individuals are described as being intellectually and developmentally normal or having no mental handicap. A 1975 literature review showed that 38 of 43 published cases of Aarskog syndrome were of average intelligence. ${ }^{4}$ However, a retrospective analysis of 52 boys with Aarskog syndrome seen over a 20 year period by Fryns concluded that the incidence of mental handicap in Aarskog syndrome might be as high as $30 \% .^{5}$

Borderline functioning (IQ from 70 to 84) and specific learning difficulties have been reported. Dysgraphia and dyslexia have been observed $^{67}$ along with other specific reading and verbal difficulties. In view of the uncertainty of developmental and intellectual outcome in Aarskog syndrome this study was devised to test the hypothesis that Aarskog syndrome is associated with an increased incidence of mild mental handicap.

\section{Patients and methods}

Boys aged $0-17$ years with a diagnosis of Aarskog syndrome were identified through a postal request sent to all British clinical genetic centres. Their families were contacted and invited to participate in the study. Families agreeing to participate were visited at home
Table 1 IQ in boys with Aarskog syndrome

\begin{tabular}{rllr}
\hline Case & Age (years) & Method & \multicolumn{1}{c}{$I Q$} \\
\hline 1 & 0.7 & Griffiths & 97 \\
2 & 1.2 & Griffiths & 98 \\
3 & 1.3 & Griffiths & 104 \\
4 & 1.4 & Griffiths & 92 \\
5 & 2.3 & Griffiths & 68 \\
6 & 2.3 & Griffiths & 102 \\
7 & 2.4 & Griffiths & 104 \\
8 & 3.8 & Griffiths & 81 \\
9 & 4.3 & Griffiths & 102 \\
10 & 5.2 & BAS & 128 \\
11 & 5.8 & BAS & 107 \\
12 & 7.5 & BAS & 116 \\
13 & 7.9 & BAS & 103 \\
14 & 8.8 & BAS & 109 \\
15 & 9.6 & BAS & 105 \\
16 & 10.5 & BAS & 117 \\
17 & 13.4 & BAS & 127 \\
18 & 13.4 & BAS & 112 \\
19 & 13.5 & BAS & 109 \\
20 & 14.3 & BAS & 125 \\
21 & 16.7 & BAS & 118 \\
\hline
\end{tabular}

Mean IQ, 106; Mean IQ for Griffiths mental development scales (Griffiths), 94; Mean IQ for British activity scales (BAS), 115.

or in the local genetic clinic and the diagnosis of Aarskog syndrome in the affected patient confirmed (by LL). Clinical photographs were assessed for facial and hand characteristic features (by MP) and the diagnosis agreed.

The Griffiths developmental assessment was used to assess boys aged $0-4$ years $(n=9)$ and the British ability scale for those aged 5-17 $(n=12)$. All clinical and developmental/ intelligence testing was carried out by LL who was trained in the use of the Griffiths mental development and British ability scales.

\section{Results}

The IQ in the 21 boys with Aarskog syndrome studied ranged from 68-128 and followed a normal distribution (table 1). There were no areas of specific difficulties within the assessments in affected boys.

\section{Discussion}

The usefulness of IQ measurement tools depends on their predictive sensitivity and their ability to be of immediate practical clinical use. Studies have found, particularly in infants, ${ }^{8}$ that many traditional tests are of little predictive value in normal children. Tests that rely heavily on sensorimotor skills are of limited use in assessing a child with small joint problems such as those that occur frequently in Aarskog syndrome.

The Griffiths mental development scales and British ability scales were chosen for their ease of application in a home environment. Although information processing assessments such as visual recognition memory and attention with a habitual stimulus are better predictors of later cognitive $\mathrm{IQ}^{89}$ when 
performed in infancy, these tests require sophisticated recording equipment and were unsuitable for this study.

A review of the literature on Aarskog syndrome suggests a problem with borderline intellectual functioning and learning difficulties in affected patients. However, there are insufficient data to assess this accurately on a population basis rather than within individual families. Many of the earlier case reports did not document IQ assessment in affected boys but used descriptive words such as "dull". ${ }^{10}{ }^{11}$ The retrospective study that demonstrated a mental handicap rate of $30 \%$ is complicated by biased ascertainment as 14 subjects were selected from a population with pre-existing mental handicap.

This study of 21 boys with Aarskog syndrome ascertained through attendance at a British genetic clinic showed a normal distribution of IQ ranging from 68-128. Even in this study, there is likely to be ascertainment bias as features of Aarskog syndrome are often seen by family members as part of a "family look" so medical attention is not sought unless the condition is complicated by medical problems. Although this study does not attempt to assess specific learning difficulties, the data presented are supportive of a normal intellectual outcome in patients with Aarskog syndrome.

This study was funded by MRC Grant No G 9315093MB. The authors thank Mr Alistair Hall, Psychologist, Glasgow University.

1 Aarskog D. A familial syndrome of short stature associated with facial dysplasia and genital anomalies. $\mathcal{F}$ Pediatr 1970;77:856-61

2 Scott CI. Unusual facies, joint hypermobility, genital nomaly and short stature: a new dysmorphic syndrome. Birth Defects: Original Article Series 1971;VII:240-6.

3 Furukawa CT, Hall BD, Smith DW. The Aarskog syndrome. F Pediatr 1972;81:1117-22.

4 Berman P, Desjardins C, Fraser FC. The inheritance of the Aarskog facial-digital-genital syndrome. F Pediatr 1975;86: 885-91.

5 Fryns JP. Aarskog syndrome: the changing phenotype with age. Am $\mathcal{F}$ Med Genet 1992;43:420-7.

6 Sugarman GI, Rimoin DL, Lachman RS. The facial-digitalgenital (Aarskog) syndrome. Am 7 Dis Child 1973;126:24852 .

7 Pederson JC, Fryns JP, Bracke P, Geeraert M, Van Den Berge H. The Aarskog syndrome. Ann Genet 1980;23:10810 .

8 Ross G. Some thoughts on the value of infant tests for assessing and predicting mental ability [see comments]. $\mathcal{F}$ Dev Behav Pediatr 1989;10:44-7.

9 Rose SA, Feldman JF, Wallace IF. Infant information processing in relation to six-year cognitive outcomes. Child Development 1992;63:1126-41.

10 Melnick M, Shieds ED. Aarskog syndrome: new oral-facial findings. Clinical Genetics 1976;9:20-4.

11 De Saxe M, Kromberg JGR, Jenkins T. The Aarskog (faciodigital-genital) syndrome in South Africa. $S$ Afr Med 7 1984;65:299-303. 